\title{
Penerapan UCD (User Centered Design) Pada Perancangan Sistem Informasi Manajemen Aset TI Berbasis Web di Bid TIK Kepolisian Daerah Kepulauan Riau
}

\author{
Supardianto $^{1 *}$, Arief Binsar Tampubolon ${ }^{2 * *}$ \\ * Teknik Informatika, Politeknik Negeri Batam \\ ** Teknik Multimedia Jaringan, Politeknik Negeri Batam \\ supardianto@polibatam.ac.id ${ }^{1}$, ariefbinsar@gmail.com²
}

\begin{tabular}{l}
\hline \hline Article Info \\
\hline Article history: \\
Received 2020-06-12 \\
Revised 2020-06-26 \\
Accepted 2020-06-29 \\
\hline
\end{tabular}

Keyword:

IT Asset Management Information System, User Centered Design, Usability.

\begin{abstract}
The process of administration and management of assets in the Information Technology and Communication Division is currently using the Microsoft Excel application. This process makes it difficult to trace and control assets. Asset management is also tricky because many inventories of each item or asset originating from other parties are not installed and damaged. This research aims to design and create a web-based IT asset management information system by implementing UCD (user-centered design). This method focuses on the user as the center of application development, such as specify the context of use, specify User and Organizational Requirements, produce design solutions, and evaluate the design. Based on result Usability Testing with System Usability Scale, the IT Asset Management Information system is in the acceptable range for grade Scale with result $C$ while on adjective ratings with good results of 76. Therefore, the IT Asset Management Information system successfully builds a user-friendly system with a good usability level.
\end{abstract}

\section{Pendahuluan}

Pengelolaan aset adalah mengelola informasi mengenai aset serta penggunaannya, seperti proses pengadaan barang, penerimaan barang, ketersediaan barang, pemasangan aset, pemeliharaan serta menghapus aset yang tidak lagi digunakan [1]. Salah satu satuan kerja (satker) yang ada didalam Polda Kepri adalah Bidang Teknologi Informasi dan Komunikasi (Bid TIK) yang bertugas terhadap pelaksanaan kegiatan teknologi informasi dan komunikasi, pengumpulan dan pengolahan data, menyediakan informasi Keamanan dan Ketertiban Masyarakat, mewujudkan penggelaran peralatan komunikasi (alkom) yang terintegrasi antara Polda dan Polres dan terwujudnya SDM personel dalam bidang Teknologi Informasi Komunikasi yang profesional dan handal, dari segi kualitas maupun kuantitas [2].

Proses administrasi dan pengelolaan aset di Bid TIK saat ini menggunakan aplikasi Microsoft Excel. Hal tersebut menyebabkan sulitnya melakukan penelusuran dan pengontrolan aset. Pengelolaan aset juga sulit karena banyak inventaris setiap barang atau aset yang berasal dari pihak lain tidak terpasang serta rusak. Menurut Baskoro selaku Kepala
Urusan Pelayanan Komunikasi (KAUR YANKOM) permasalahan tersebut menyebabkan pengelola aset sulit dilakukan. Permasalahan tersebut menyebabkan proses untuk menggantikan aset yang telah rusak kepada pihak lain menjadi tidak maksimal.

Solusi yang dapat diajukan untuk mengatasi permasalahan tersebut adalah menyediakan sebuah aplikasi pengelolaan yang dapat mengelola proses manajemen aset menjadi lebih baik dan terstruktur sehingga pengelolaan dan monitoring aset pada Bid TIK mudah dilakukan.

Pengimplementasian aplikasi pengelolaan aset dirancang agar tertib dokumentasi dan administrasi. Tertib dokumentasi bertujuan agar ketersedian terhadap data dokumen mengenai penggunaan aset, sedangkan tertib administrasi agar bisa menjamin berjalannya prosedur pengelolaan aset mulai pada saat pengadaan, perubahan, sampai penghapusan data aset [3]. Aplikasi pengelolaan aset harus dapat melakukan pengelolaan aset seperti memberikan informasi nilai aset, jumlah perangkat yang tersedia, waktu pemeliharaan aset, biaya perawat, informasi mengenai software dan hardware, dan penghapusan aset dari sistem [4]. 
Berdasarkan permasalahan yang diatas maka dibutuhkan aplikasi yang dapat mengelola aset. Rancangan aplikasi dibangun dengan menggunakan model pengembangan aplikasi UCD (user centered design) agar aplikasi yang dirancang sesuai tujuan dan memenuhi kebutuhan pengguna. Penggunan metode UCD dapat menghasilkan aplikasi yang mudah dimengerti oleh pengguna [5]. Aplikasi yang dirancang juga dapat menyediakan data berupa jumlah komputer dan laptop yang tersedia dan dapat di-install, informasi terkait nilai aset, informasi terhadap pemeliharaan aset, informasi biaya dalam merawat aset, informasi aset perangkat keras, informasi aset perangkat lunak, informasi dalam menghapus aset, dan pembuatan laporan aset.

\section{LANDASAN TEORI}

\section{A. Sistem Informasi Manajemen Aset}

Sistem informasi manajemen aset merupakan perangkat lunak atau aplikasi pengelolaan barang atau aset yang digunakan pada perusahaan yang memiliki aset dalam jumlah banyak sehingga sulit melakukan pengelolaan dan membutuhkan sebuah divisi tersendiri untuk pengelolaan aset [6].

Dengan memanfaatkan teknologi seperti sistem informasi, maka akan dapat membantu perusahaan untuk fokus terhadap tujuan dan pengelolaan aset. Sistem informasi yang menggunakan jaringan intranet juga dapat dimanfaatkan oleh pihak perusahaan untuk melakukan pemeriksaan dan pengawasan terhadap aset. Pembuatan perangkat lunak sistem informasi ini menyediakan beberapa fitur yang digunakan untuk mengelola aset seperti pemeriksaan aset, permintaan aset, pembelian, input data, menghapus data aset, hingga membuat laporan akhir [7].

\section{B. User Centered Design}

User centered design (UCD) disebut human centered design. Human centered design merupakan suatu metode yang dimanfaatkan untuk pengembangan sistem secara interaktif yang bertujuan untuk membuat sebuah perangkat lunak atau sistem [8].

User centered design adalah tahapan-tahapan desain antarmuka yang berfokus pada kegunaan, kebutuhan pengguna, lingkungan, tugas, dan alur kerja pada desainnya. Hal-hal yang perlu diperhatikan dalam UCD:

- Target pengembangan aplikasi adalah pengguna

- Perancangan terstruktur atau terintegrasi

- Proses pengujian dari awal hingga akhir melibatkan pengguna

- Perancangan interaktif

Dalam metode UCD, ada 4 tahapan yang harus dilalui secara iterasi seperti pada Gambar 1.

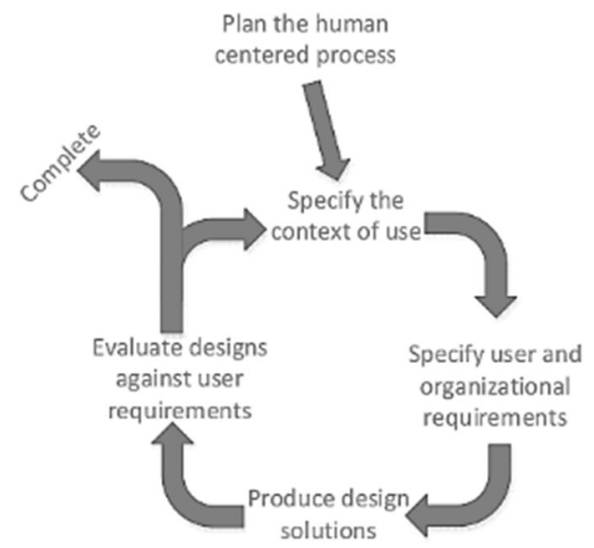

Gambar 1.Tahapan-tahapan User Centered Design [9]

Keterangan gambar:

1) Specify the context of use

Mengindentifikasi pengguna yang akan menggunakan aplikasi.

2) Specify User and Organizational Requirements Mengidentifikasi apa saja yang pengguna butuhkan terhadap aplikasi.

3) Produce Design Solutions

Merancang desain sebagai bagian dari mewujudkan solusi dari aplikasi yang sedang dirancang.

4) Evaluate Design

Mengevaluasi desain yang telah selesai dilakukan pada tahapan yang dibuat sebelumnya.

\section{Usability}

Usability adalah tingkat kemudahan pengguna ketika menggunakan aplikasi atau sebuah sistem [10] [11]. Usability yang baik yaitu pengguna dapat menggunakan aplikasi secara cepat (effective), mendapatkan kepuasan (satisfaction), serta cara penggunaan aplikasi yang sederhana (efficiency) sebagai tingkat apakah suatu produk mudah untuk digunakan.

Berdasarkan ISO usability dapat diartikan sebagai efektif, efesiensi, dan kepuasan yang ditentukan oleh pengguna dalam mencapai tujuan yang telah ditentukan sebelumnya. Tingkat usabilitas suatu website dapat berbeda-beda dan tergantung bagaimana pengguna dapat menyelesaikan serangkaian task. Beberapa parameter yang dapat dijadikan patokan dalam mengukur kriteria-kriteria web usability adalah sebagai berikut [12]:

- Learnability

- Efficiency

- Memorability

- Errors

- Satisfaction

\section{Pengujian Black Box}

Pengujian terhadap aplikasi yang dirancang dengan menggunakan metode black box. Black box merupakan pengujian yang digunakan untuk menguji fungsional terhadap suatu aplikasi yang telah dirancang [13]. Pengujian black 
box dapat digunakan untuk mengidentifikasi serta memperbaiki kesalahan dalam kondisi sebagai berikut:

- Fungsi-fungsi yang tidak berjalan sesuai perancangan

- Kesalahan yang terdapat pada user interface.

- Error pada basis data atau data eksternal.

- Error kinerja pada aplikasi.

- Inisialisasi dan kesalahan terminasi

\section{E. Usability Testing}

Pengujian usability terhadap aplikasi yang dirancang dengan menggunakan metode System Usability Scale (SUS). SUS merupakan alat survei yang dipergunakan untuk mengukur sejauh mana tingkat kegunaan suatu sistem sehingga dapat diketahui apakah sistem tersebut memiliki manfaat bagi pengguna atau tidak. Metode SUS menggunakan kusioner yang memiliki 10 butir pertanyaan dengan pengukuran jawaban menggunakan skala likert [14].

Pernyataan ganjil $(1,3,5,7,9)$ bersifat positif sedangkan pernyataan genap $(2,4,6,8,10)$ bersifat negatif. Rentang skala likert disusun dari kiri ke kanan dengan skor 1 (sangat tidak setuju), 2 (kurang setuju), 3 (ragu-ragu), 4 (setuju), 5 (sangat setuju). Cara pengolahan data SUS sebagai berikut:

1. Perhitungan skor setiap pernyataan nomor ganjil $(1,3,5,7,9)$ diperoleh dari nilai jawaban yang dipilih kemudian dikurangi 1 .

2. Untuk setiap pernyataan nomor genap memiliki skor awal $=5$. Sehingga perhitungan skor setiap pernyataan nomor genap diperoleh dengan cara skor awal (5) dikurangi nilai jawaban yang dipilih.

3. Hasil skor setiap pertanyaan dijumlahkan kemudian dikalikan dengan 2.5 sehingga skor SUS antara 0 sampai dengan 100. Perhitungan dengan menggunakan rumus berikut:

Skor SUS $=(((\mathrm{Q} 1-1)+(5-\mathrm{Q} 2)+(\mathrm{Q} 3-1)+(5-$ $\mathrm{Q} 4)+(\mathrm{Q} 5-1)+(5-\mathrm{Q} 6)+(\mathrm{Q} 7-1)+(5-\mathrm{Q} 8)+$ $(\mathrm{Q} 9-1)+(5-\mathrm{Q} 10)) * 2.5)$

Untuk mengetahui interpretasi dari skor SUS yang diperoleh dapat dilakukan dengan membandingkan skor ratarata SUS dengan rentang nilai adjective ratings, acceptability scores, dan grading scale yang ditunjukan pada Gambar 2 [15].

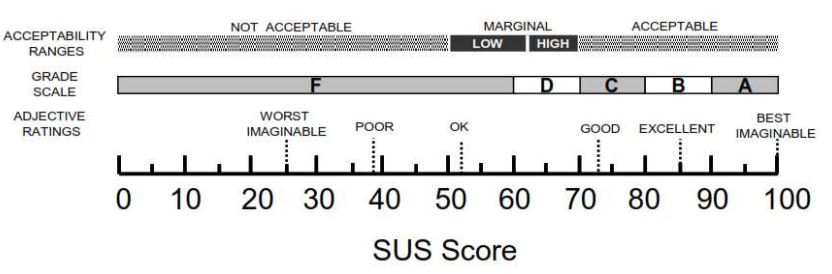

Gambar 2. Rentang nilai skor rata rata SUS berdasarkan nilai adjective ratings, acceptability scores, dan grading scales [15]

\section{Analisis dan Perancangan}

\section{A. Analisis Masalah}

Analisis masalah adalah merupakan tahapan awal yang dilakukan pada analisis sistem. Masalah dapat diartikan sebagai suatu kondisi terkait kondisi yang dibutuhkan untuk dicarikan solusi, sehingga menyebabkan tujuan dari sistem tidak tercapai. Berdasarkan hasil wawancara dengan Baskoro Widiarso, S. Kom. selaku Kepala Urusan Pelayanan Komunikasi (KAUR YANKOM) kondisi yang ada saat ini menyebabkan pengelola aset di BID TIK kesulitan untuk mendapatkan informasi atau data mengenai kondisi aset yang ada, seperti baik, rusak maupun hilang.

Proses administrasi dan pengelolaan aset di Bid TIK saat ini menggunakan aplikasi Microsoft Excel. Masalah yang ada adalah banyaknya data barang aset dan alokasi barang aset ke pegawai tidak terkordinasi dengan kondisi aset tersebut baik ataupun rusak maupun hilang, jadi tidak memungkinkan untuk dilakukan proses input data manual seperti dengan Microsoft Excel atau Microsoft Office. Selain itu, banyaknya data-data barang inventaris menyebabkan terjadinya banyak duplikasi data.

\section{B. Deskripsi Sistem}

Pada Gambar 3 terdapat client yang menggunakan web browser untuk dapat mengakses aplikasi yang diletakan pada server. Pengguna aplikasi dapat memasukan data yang ada di tampilan aplikasi kemudian data tersebut akan dikirimkan ke server. Pada server, data yang telah diisikan tersebut akan dikirim ke-database (MySQL) untuk disimpan.

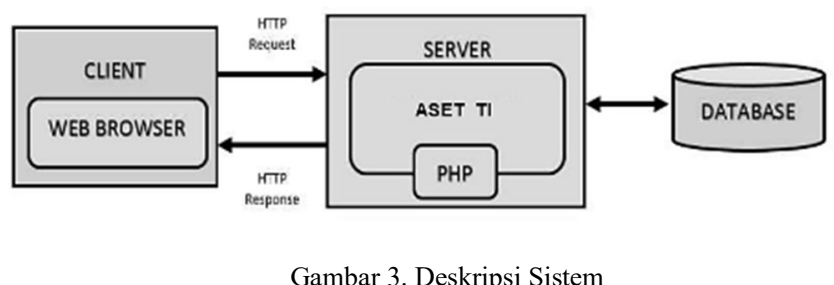

\section{Diagram Usecase}

Untuk membantu proses perancangan dalam mendeskripsikan sebuah interaksi antara satu atau lebih pengguna/aktor dengan sistem yang dirancang maka digunakan diagram Use case. Use case pada sistem dapat dilihat pada Gambar 4. 


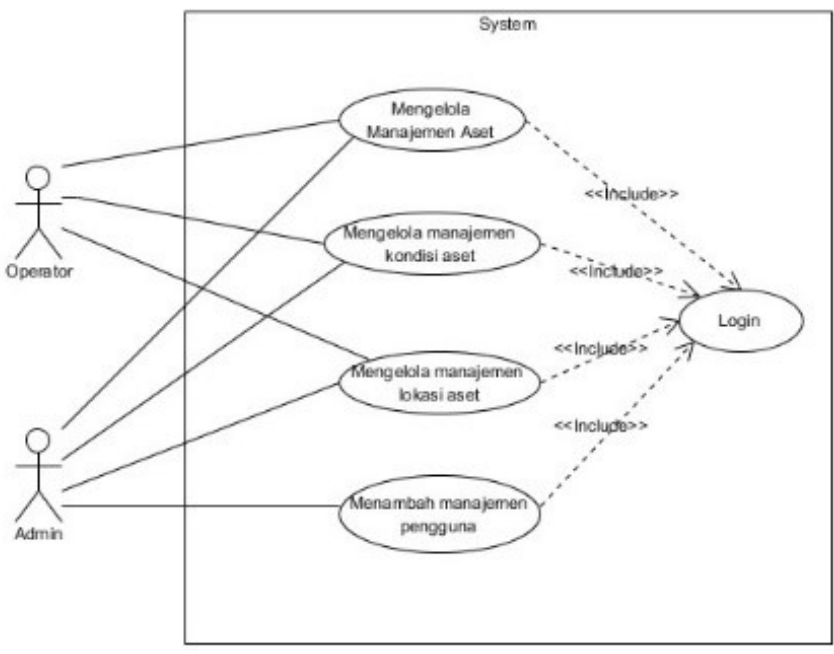

Gambar 4. Diagram Use case

\section{Diagram Class}

Diagram class sistem informasi manajemen aset TI pada Gambar 4 merupakan penggambaran sistem dari sisi definisi kelas untuk membangun sistem.

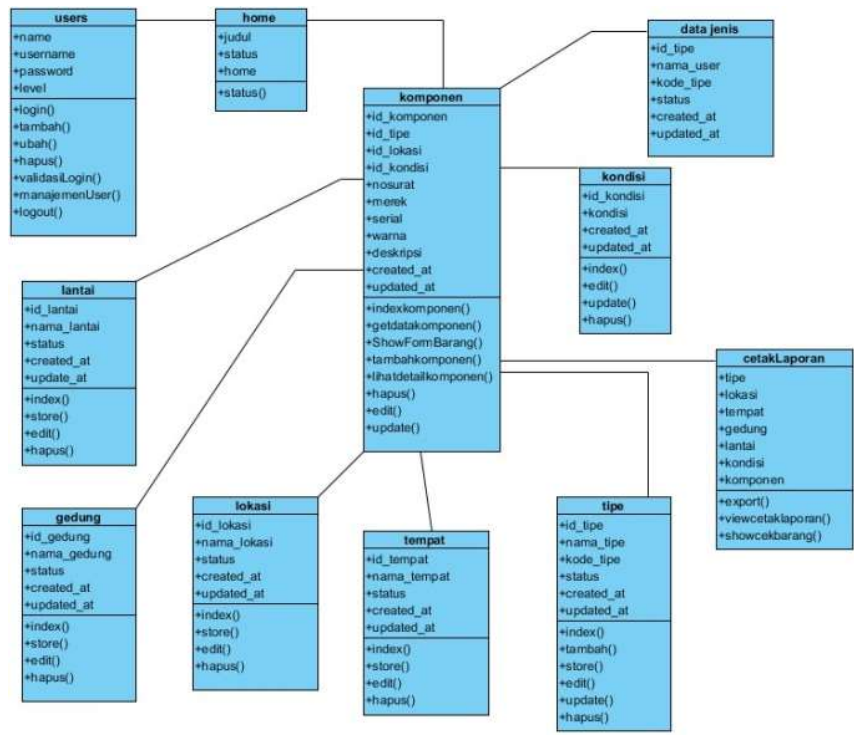

Gambar 4. Diagram Class

\section{E. EERD (Enhanced Entity Relational Diagram)}

Perancangan EERD pada aplikasi ini dapat dilihat pada Gambar 5.

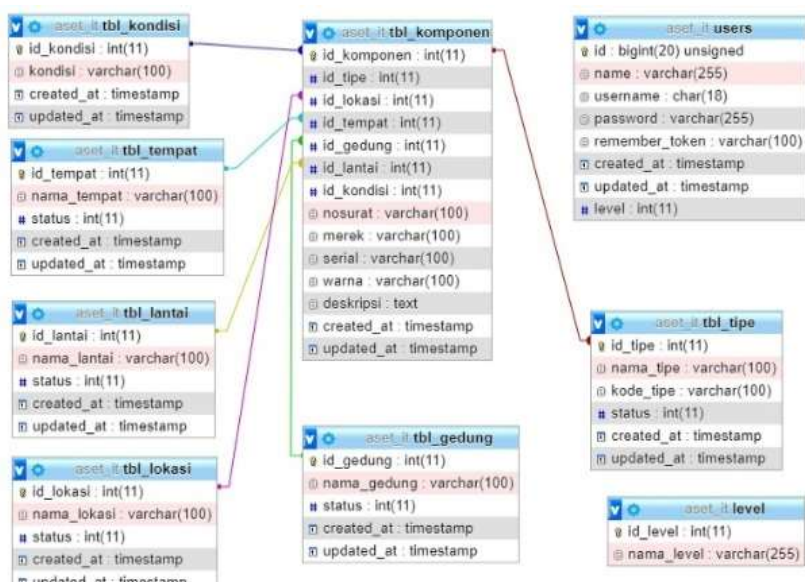

Gambar 5. Diagram EERD

\section{F. Plan the human centered process}

Pada tahap ini dilakukan analisis dasar teori, serta metode yang bertujuan untuk mendapatkan kebutuhan yang dapat membantu jalannya penelitian. Pada analisis dasar teori digunakan buku-buku dan jurnal sebagai referensi yang akan digunakan oleh peneliti.

\section{G. Specify the context of use}

Tahap ini merupakan memahami siapa pengguna dari aplikasi yang dirancang.

\section{H. Specify user and organizational requirement}

Pada proses ini peneliti akan melakukan analisis kebutuhan berupa populasi dan sampel, jenis data, sumber data seperti apa yang akan digunakan dan kebutuhan fungsional dari sistem informasi manajemen aset TI dalam penelitian ini. Populasi penelitian ini adalah anggota kepolisian dan pegawai negeri sipil di lingkungan Polri pada satuan kerja Bid TIK Polda Kepri. Sampel dalam penelitian ini adalah anggota kepolisian dan pegawai negeri sipil di lingkungan Polri pada satuan kerja Bid TIK Polda Kepri yang berjumlah 28 orang. Data yang didapatkan merupakan hasil wawancara dan angket kuesioner SUS yang dirancang sesuai dengan kebutuhan penelitian.

\section{Product Design Solution}

Mewujudkan solusi dengan melakukan perancangan yang kongkrit yakni sistem informasi manajemen aset TI yang akan dirancang. 


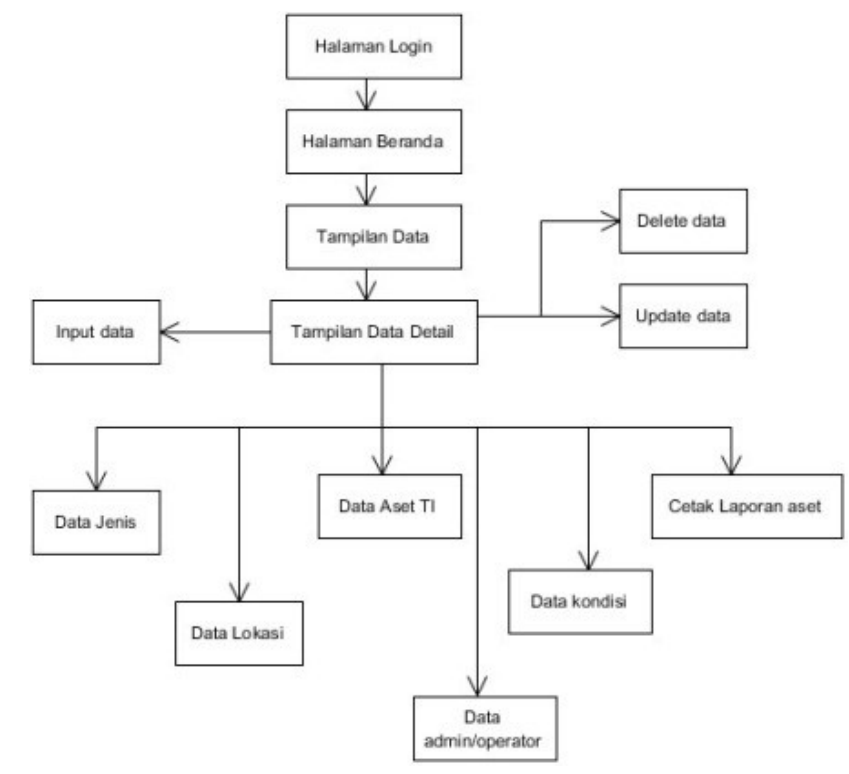

Gambar 6. Struktur Menu

Gambar 6 menunjukkan struktur menu yang dibangun dalam sistem ini. Pengguna (admin/operator) memulai sistem ini dari halaman login, kemudian setelah proses login terdapat menu tampilan data di halaman beranda. Tampilan data disini menampilkan summary dari data-data yang diinput dalam sistem informasi manajemen aset TI. Selanjutnya pengguna dapat memilih kategori di tampilan data untuk melihat data detail dan untuk input data. Dalam tampilan data detail tersebut terdapat menu update atau ubah data, delete atau hapus data dan tambah data. Kemudian untuk menu tambah data, terdapat masing-masing form input untuk semua kategori yang ada dalam sistem ini.

\section{J. Evaluate design against user requirements}

Tahapan ini dilakukan perencanaan pengujian sistem informasi manajemen aset TI yang terdiri dari:

- Penentuan tolak ukur pengujian. Untuk dapat mengukur usability secara dalam pengujian. Serta membuat pertanyaan uji yang akan dimasukan ke dalam kuisioner saat pengambilan data.

- Menentukan strategi dan penilaian pengukuran. Pengukuran dilakukan dengan menentukan cara pengukuran dan penentuan tingkat tercapainya usability.

- Merumuskan fitur yang akan diterapkan berdasarkan masing-masing strategi dari pengukuran yang didapat.

\section{K. Evaluasi dengan Metode System Usability Scale (SUS)}

Tahapan pengujian usability dilakukan dengan menggunakan metode SUS. Tahapan evaluasi diawali mewujudkan minimum viable product dari rancangan yang akan dibuat, setelah itu pengguna akan menggunakan aplikasi terlebih dahulu seperti login. Pengguna kemudian melakukan testing dan demonstrasi terhadap aplikasi. Setelah melakukan demonstrasi pengguna mengisi kuesioner SUS yang terdiri dari 10 butir pernyataan dengan menggunakan skala likert. Rentang nilai skala likert disusun dari kiri ke kanan dengan skor 1 -5. Daftar penyataan dapat dilihat pada Tabel I.

TABEL I

IDENTIFIKASI AKTOR

\begin{tabular}{|c|c|c|c|c|c|c|}
\hline No & $\begin{array}{c}\text { Pernyataan } \\
\end{array}$ & 1 & 2 & 3 & 4 & 5 \\
\hline 1 & $\begin{array}{l}\text { Saya berpikir bahwa saya akan } \\
\text { ingin lebih sering menggunakan } \\
\text { aplikasi ini }\end{array}$ & & & & & \\
\hline 2 & $\begin{array}{l}\text { Saya menemukan bahwa aplikasi ini } \\
\text { tidak harus serumit ini }\end{array}$ & & & & & \\
\hline 3 & $\begin{array}{l}\text { Saya pikir aplikasi ini mudah } \\
\text { digunakan }\end{array}$ & & & & & \\
\hline 4 & $\begin{array}{l}\text { Saya pikir bahwa saya akan } \\
\text { membutuhkan bantuan dari orang } \\
\text { teknis untuk dapat menggunakan } \\
\text { aplikasi ini }\end{array}$ & & & & & \\
\hline 5 & $\begin{array}{l}\text { Saya menemukan berbagai fungsi } \\
\text { diaplikasi ini diintergrasikan dengan } \\
\text { baik }\end{array}$ & & & & & \\
\hline 6 & $\begin{array}{l}\text { Saya pikir ada terlalu banyak } \\
\text { ketidaksesuaian dalam aplikasi ini }\end{array}$ & & & & & \\
\hline 7 & $\begin{array}{l}\text { Saya bayangkan bahwa kebanyakan } \\
\text { orang akan mudah untuk } \\
\text { mempelajari aplikasi ini dengan } \\
\text { sangat cepat }\end{array}$ & & & & & \\
\hline 8 & $\begin{array}{l}\text { Saya menemukan aplikasi ini sangat } \\
\text { rumit untuk digunakan }\end{array}$ & & & & & \\
\hline 9 & $\begin{array}{l}\text { Saya merasa sangat percaya diri } \\
\text { untuk menggunakan aplikasi ini }\end{array}$ & & & & & \\
\hline 10 & $\begin{array}{l}\text { Saya perlu belajar banyak hal } \\
\text { sebelum saya bisa memulai } \\
\text { menggunakan aplikasi ini }\end{array}$ & & & & & \\
\hline
\end{tabular}

Untuk mengetahui interprestasi skor SUS yang diperoleh dapat dilakukan dengan membandingkan antara skor rata-rata SUS dengan rentang nilai adjective rating, acceptability scores, dan grading scales.

\section{IMPLEMENTASI DAN PENGUJIAN}

\section{A. Konteks Pengguna}

Menerapkan tahapan demi tahapan pada metode UCD yang digunakan untuk mengidentifikasi permasalahan yang dilakukan dengan metode wawancara kepada calon pengguna. Tabel II akan mendeskripsikan aktor dan deskripsi dari aktor penguna aplikasi yang dirancang.

TABEL III

IDENTIFIKASI AKTOR

\begin{tabular}{|l|l|}
\hline Aktor & \multicolumn{2}{|c|}{ Deskripsi } \\
\hline Admin & Admin merupakan pengguna aplikasi yang dapat \\
& menjalankan fitur-fitur yang terdapat pada aplikasi \\
& dari sisi admin, antara lain melihat dan \\
& menambahkan Manajemen Aset, melakukan cetak \\
& laporan aset, melihat dan menambahkan Manajemen \\
& Lokasi Aset, melihat dan menambahkan Manajemen \\
\hline
\end{tabular}




\begin{tabular}{|l|l|}
\hline Aktor & \multicolumn{1}{|c|}{ Deskripsi } \\
\hline Operator & $\begin{array}{l}\text { Kondisi Aset serta melihat dan menambahkan } \\
\text { Manajemen Pengguna. }\end{array}$ \\
& $\begin{array}{l}\text { Admin merupakan pengguna aplikasi yang dapat } \\
\text { menjalankan fitur-fitur yang telah disediakan oleh } \\
\text { aplikasi dari sisi admin, antara lain melihat dan } \\
\text { menambahkan Manajemen Aset, melakukan cetak } \\
\text { laporan aset, melihat dan menambahkan Manajemen } \\
\text { Lokasi Aset, melihat dan menambahkan Manajemen } \\
\text { Kondisi Aset. }\end{array}$ \\
\hline
\end{tabular}

\section{B. Kebutuhan Pengguna}

Dari pertanyaan yang telah dijawab oleh responden pada kuesioner yang dibagikan, dihasilkan beberapa jawaban dari 28 responden untuk mendapatkan kesimpulan saran dan masukan terhadap antarmuka Sistem Informasi Manajemen Aset TI, yaitu:

1. Halaman login yang simple dan paham saat digunakan.

2. Halaman beranda yang sederhana, dengan status/kondisi dari aset yang sarankan oleh pengguna dan tidak terdapat tampilan yang tidak penting.

3. Halaman Manajemen Kondisi dan Lokasi Aset agar dapat di custom sesuai dengan keinginan operator saat mengisikan data.

4. Hasil cetak laporan aset mengikuti dari format form yang ada diinstansi, direkomendasikan oleh operator agar tidak mengerjakan berulang.

5. Tampilan dan struktur navigasi menu konsisten mengikuti yang ada di instansi agar tidak menyuitkan operator

\section{Implementasi Perancangan}

Implementasi adalah tahapan ketika pembuatan aplikasi dilakukan setelah melalui tahapan analisis dan desain antarmuka. Implementasi pendekatan UCD menghasilkan antarmuka seperti berikut:

\section{1) Halaman Login}

Pada halaman login terdapat 2 hak akses. Halaman khusus untuk administrator dan halaman lainnya merupakan halaman-halaman pilihan yang dapat diakses oleh operator. Halaman yang dapat diakses khusus administrator di antaranya adalah login untuk identifikasi akun pengguna. Antarmuka untuk halaman login dapat dilihat pada Gambar 7.

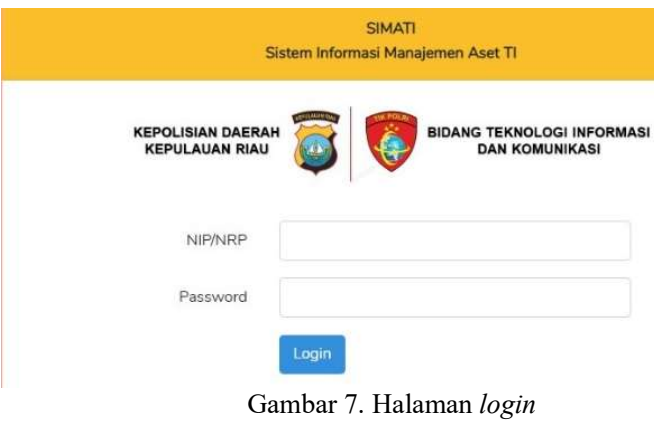

2) Halaman Beranda
Pada halaman beranda, admin dan operator dapat mengetahui status terkini kondisi dan total kuantitas dari aset seperti kondisi rusak berat, rusak sedang, rusak ringan, baik, dan deperbaiki, untuk memudahkan dalam melihat dibantu dengan diagram pie. terlihat pada Gambar 8.

\section{SIMATI - Sistem Informasi Manajemen Aset TI}

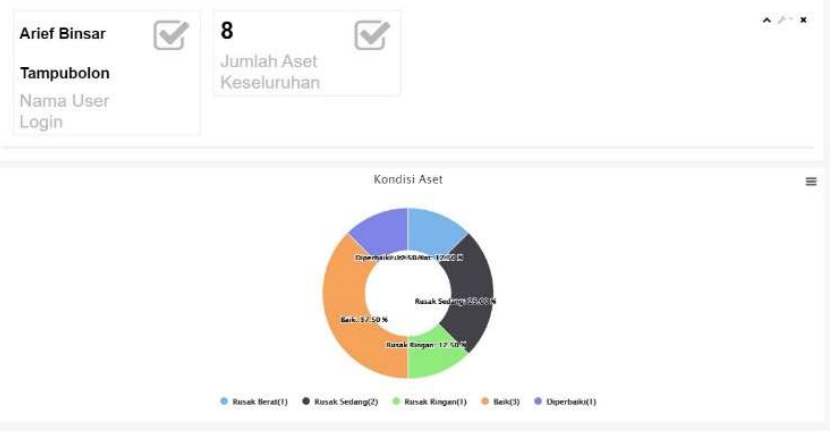

Gambar 8. Halaman beranda

\section{3) Halaman Manajemen Aset}

Pada halaman manajemen aset terdapat tiga (3) submenu yaitu Data Aset, Jenis Aset dan Cetak Laporan. Pada Data Aset, admin dan operator dapat mengelola (tambah, hapus dan ubah) data aset dengan memasukkan data sesuai dengan kolom yang tersedia pada Gambar 9.

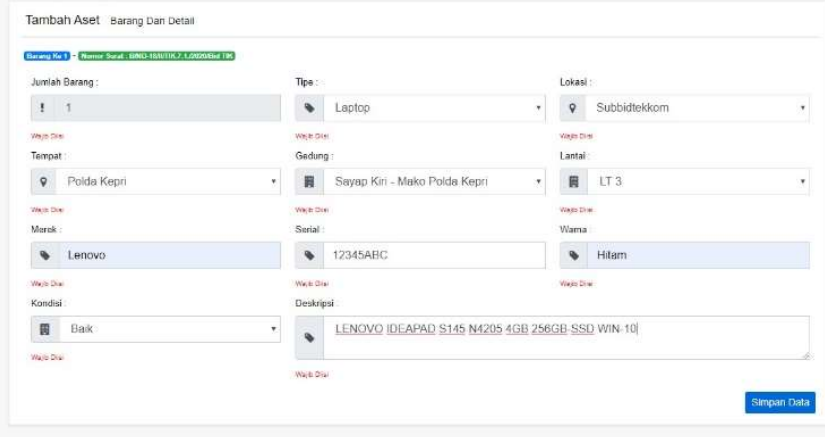

Gambar 9. Halaman form tambah aset

Sedangkan hasilnya pada Gambar 10 adalah data masukan yang sudah ada dalam database sesuai dengan kolom data masukan dalam form aset berisi deskripsi aset atau detail aset dari inputan

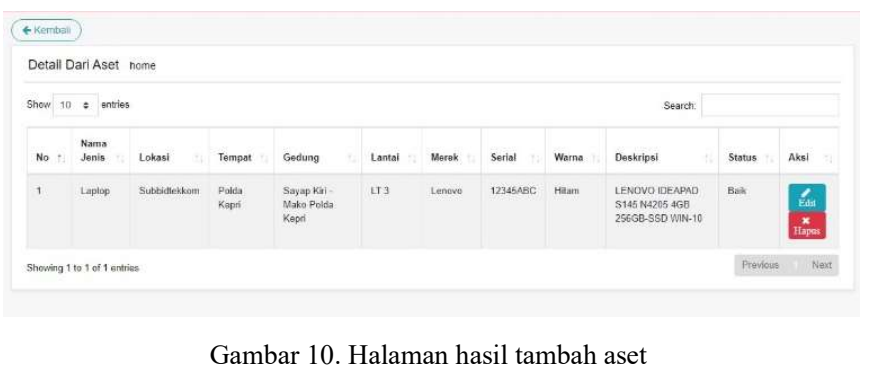

Pada Jenis Aset, admin dan operator dapat mengelola (tambah, hapus dan ubah) data jenis aset dengan memasukkan 
nama jenis dan kode jenis, seperti nama jenis $=$ Flasdisk dan kode jenis $=$ FDK terlihat pada Gambar 11 .

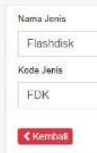

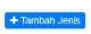

Gambar 11. Halaman tambah jenis aset

Sedangkan hasilnya pada Gambar 12 adalah data masukan yang sudah ada dalam database sesuai dengan kolom data masukan dalam form jenis aset untuk mengetahui jenis perangkat aset.

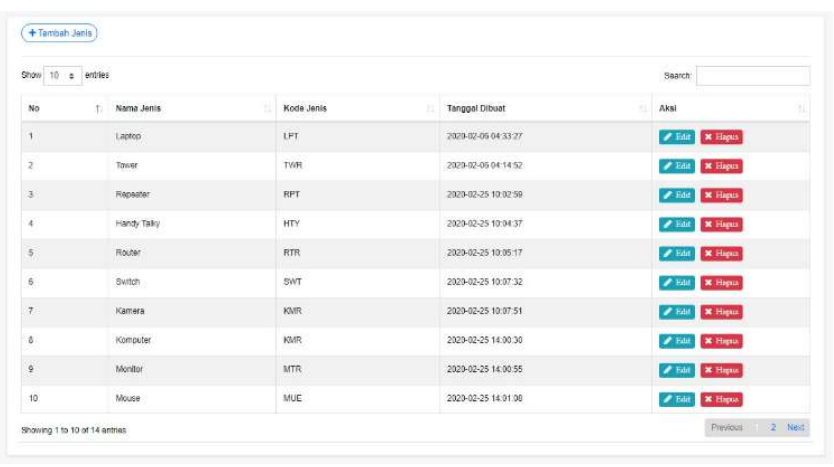

Gambar 12. Halaman hasil tambah jenis aset

Gambar 13 merupakan halaman detail kondisi yang mana aset yang ditambah terkompulir berdasarkan kategori jenis, kondisi aset dan jumlah setiap kategori dari aset, sehingga statistik dari aset dapat terlihat.

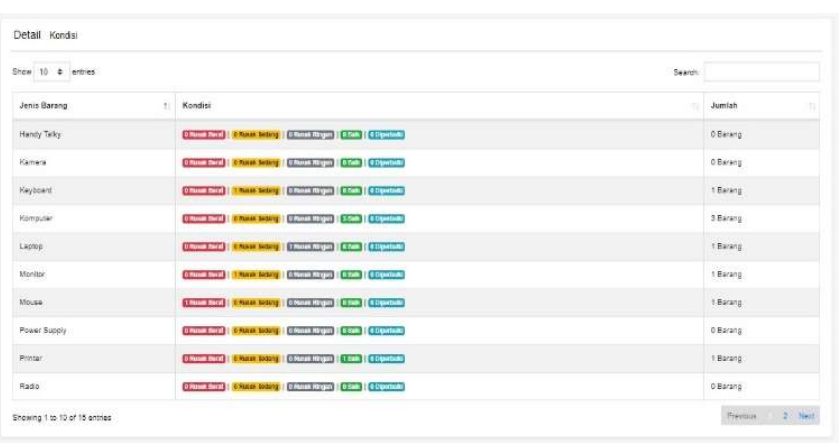

Gambar 13. Halaman detail kondisi

Pada Cetak Laporan, admin dan operator dapat mengambil laporan aset dengan mengunduh softcopy berormat *.pdf atau langsung dicetak menjadi hardcopy dengan memasukkan rentang tanggal pencarian aset pada tanggal aset terlihat pada Gambar 13.

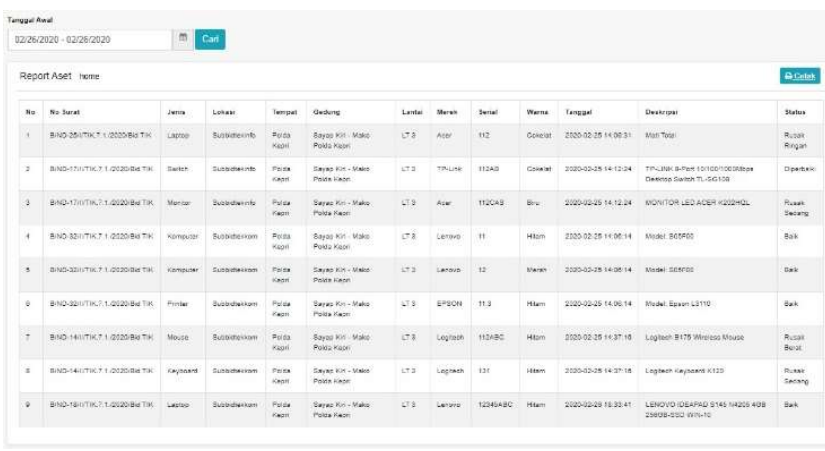

Gambar 13. Halaman cetak laporan aset

Sedangkan hasilnya pada Gambar 14 adalah data masukan yang sudah ada dalam database sesuai dengan kolom data masukan dalam form cetak laporan. Desain form cetak laporan disesuaikan dengan kebutuhan dan keperluan dinas yang berlaku di Bid TIK Polda Kepulauan Riau.
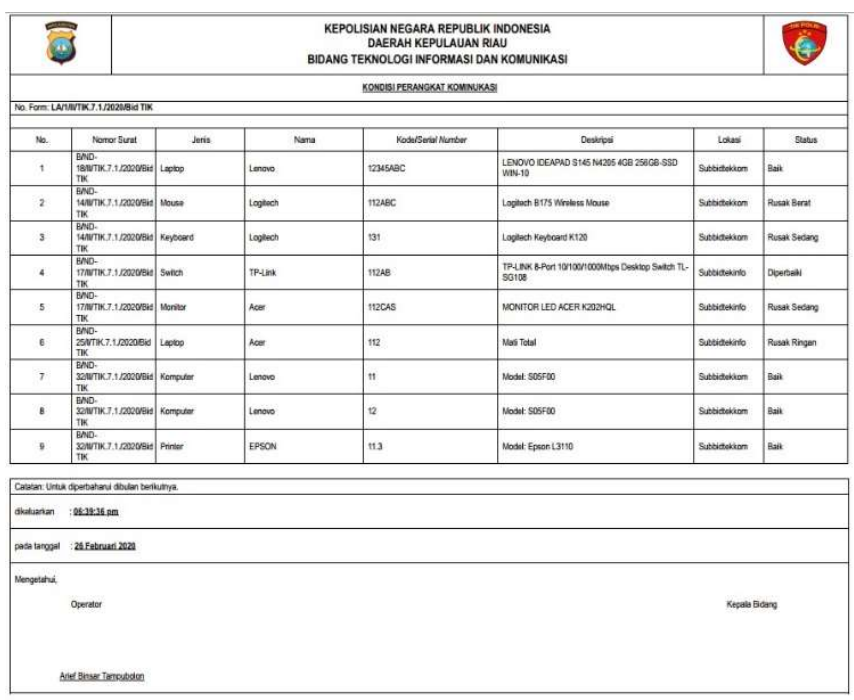

Gambar 14. Hasil cetak laporan aset

\section{4) Halaman Manajemen Lokasi Aset}

Pada halaman Manajemen lokasi Aset, admin dan operator dapat mengelola (tambah, hapus dan ubah) data lokasi aset berada seperti wilayah, lokal, gedung dan lantai untuk memudahkan dalam pemetaan tempat aset berada. Pada gambar 15 ditunjukan gambar salah contoh lokasi aset berupa wilayah.

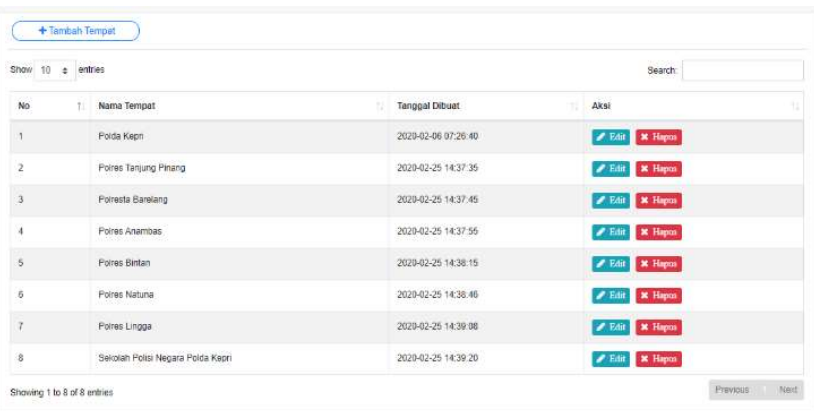


Gambar 15. Halaman wilayah aset

\section{5) Halaman Manajemen Kondisi Aset}

Pada halaman Manajemen Kondisi Aset, admin dan operator dapat mengelola (tambah, hapus dan ubah) data kondisi aset seperti pada Gambar 19 dengan menekan tombol tambah kondisi aset dan isinya dapat disesuaikan.

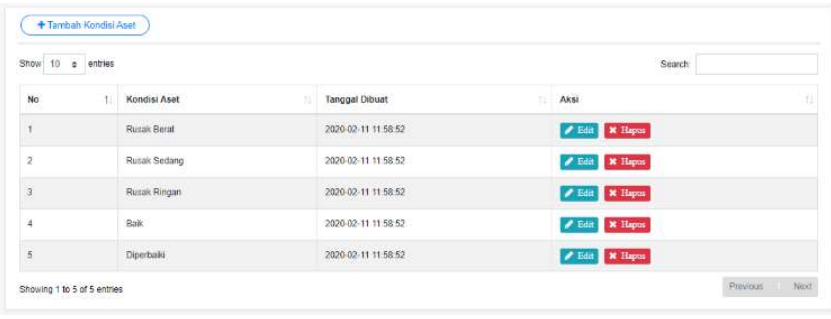

Gambar 16. Halaman manajemen kondisi aset

\section{6) Halaman Manajemen Pengguna}

Pada halaman Manajemen Pengguna pada Gambar 17 terdapat list akun pengguna, admin menambahkan admin atau operator yang dapat mengakses sistem informasi manajemen aset TI.

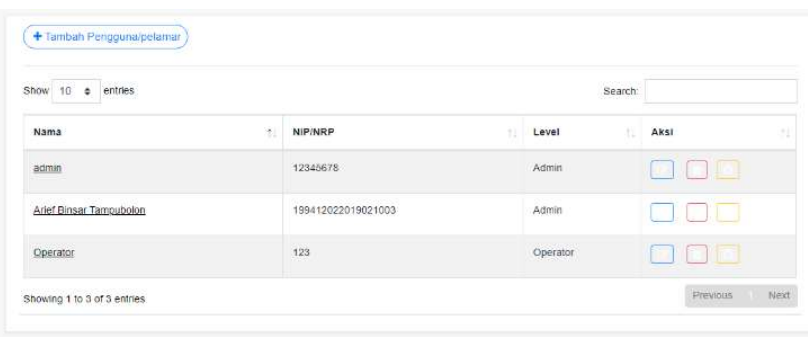

Gambar 17. Halaman manajemen pengguna

Pada Gambar 18 admin dapat menambahkan pengguna. NIP/NRP merupakan angka nomor induk sama halnya NIK pada KTP, name adalah nama dari operator, password yang mudah diingat tetapi susah ditebak, dan level adalah hak akses dari akun. NIP/NRP berupa angka NRP sebanyak 8 digit untuk anggota polri, sedangkan NIP untuk PNS Polri sebanyak 18 digit dan password minimal 8 karakter berupa huruf, angka dan simbol.

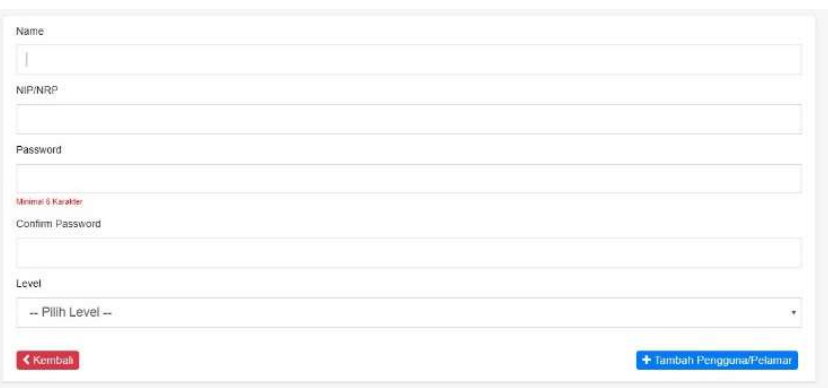

Gambar 18. Halaman tambah pengguna

Untuk mengganti password seperti pada Gambar 19 dapat dilakukan oleh akun admin dan operator dengan memasukkan password lama lalu memasukkan password baru dan konfirmasi password baru, hanya saja operator tidak dapat menambahkan akun pengguna.

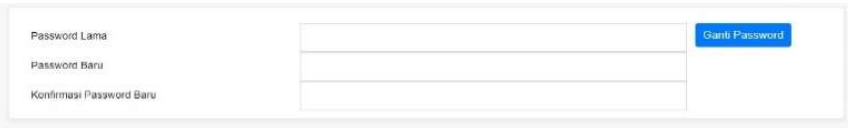

Gambar 19. Halaman ganti password pengguna

\section{Pengujian}

Pengujian dilakukan dengan menunjukkan Sistem Informasi Manajemen Aset TI kepada responden dan meminta respon dengan mengisi kuisioner SUS.

\section{1) Pengujian Usability}

Pengujian usability menggunakan metode SUS dilakukan dengan membagikan kuesioner kepada 28 responden dengan berbagai latar belakang usia dan pekerjaan. Kuesioner terdiri dari 10 pernyataan yang memiliki sifat positif pada pernyataan ganjil dan sifat negatif pada penyataan genap dengan batasan skala antara 1 sampai dengan 5. Adapun hasil pengujian dengan menggunakan metode SUS dapat dilihat pada Tabel III.

TABEL IIIII

SKOR PENGISIAN KUISIONER SUS

\begin{tabular}{|c|c|c|c|c|c|c|c|c|c|c|c|c|c|}
\hline \multirow{2}{*}{ No } & \multirow{2}{*}{ Reponden } & \multirow{2}{*}{ Usia } & \multirow{2}{*}{$\begin{array}{c}\text { Jenis } \\
\text { Kelamin }\end{array}$} & \multicolumn{10}{|c|}{ Skor Asli } \\
\hline & & & & Q1 & Q2 & Q3 & Q4 & Q5 & Q6 & Q7 & Q8 & Q9 & Q10 \\
\hline 1 & Responden 1 & 33 & Laki-Laki & 5 & 2 & 4 & 2 & 4 & 2 & 4 & 1 & 5 & 2 \\
\hline 2 & Responden 2 & 51 & Laki-Laki & 3 & 4 & 5 & 1 & 5 & 2 & 3 & 1 & 5 & 3 \\
\hline 3 & Responden 3 & 20 & Laki-Laki & 4 & 2 & 4 & 2 & 3 & 2 & 3 & 2 & 4 & 1 \\
\hline 4 & Responden 4 & 33 & Laki-Laki & 5 & 3 & 5 & 3 & 5 & 2 & 5 & 3 & 5 & 3 \\
\hline 5 & Responden 5 & 20 & Laki-Laki & 5 & 2 & 4 & 2 & 4 & 2 & 4 & 2 & 5 & 2 \\
\hline 6 & Responden 6 & 54 & Laki-Laki & 3 & 2 & 3 & 2 & 4 & 3 & 5 & 2 & 4 & 2 \\
\hline 7 & Responden 7 & 23 & Laki-Laki & 4 & 2 & 4 & 2 & 4 & 2 & 4 & 2 & 3 & 2 \\
\hline 8 & Responden 8 & 23 & Laki-Laki & 3 & 2 & 4 & 2 & 5 & 3 & 5 & 2 & 3 & 1 \\
\hline 9 & Responden 9 & 24 & Laki-Laki & 4 & 2 & 3 & 2 & 4 & 2 & 4 & 2 & 4 & 1 \\
\hline 10 & Responden 10 & 50 & Perempuan & 4 & 2 & 4 & 3 & 4 & 2 & 4 & 2 & 3 & 2 \\
\hline 11 & Responden 11 & 47 & Laki-Laki & 3 & 2 & 3 & 3 & 4 & 2 & 3 & 2 & 3 & 2 \\
\hline 12 & Responden 12 & 32 & Laki-Laki & 5 & 2 & 4 & 2 & 4 & 1 & 2 & 3 & 4 & 3 \\
\hline 13 & Responden 13 & 51 & Perempuan & 5 & 2 & 4 & 2 & 4 & 2 & 4 & 1 & 5 & 2 \\
\hline 14 & Responden 14 & 25 & Laki-Laki & 4 & 2 & 5 & 2 & 4 & 1 & 3 & 2 & 4 & 2 \\
\hline 15 & Responden 15 & 38 & Laki-Laki & 4 & 2 & 4 & 2 & 4 & 3 & 3 & 2 & 4 & 2 \\
\hline 16 & Responden 16 & 21 & Laki-Laki & 3 & 2 & 3 & 2 & 4 & 1 & 3 & 2 & 5 & 2 \\
\hline 17 & Responden 17 & 24 & Laki-Laki & 4 & 2 & 4 & 2 & 3 & 3 & 4 & 2 & 4 & 2 \\
\hline 18 & Responden 18 & 25 & Laki-Laki & 3 & 1 & 4 & 1 & 3 & 1 & 4 & 1 & 3 & 2 \\
\hline 19 & Responden 19 & 32 & Perempuan & 5 & 2 & 5 & 2 & 5 & 2 & 5 & 1 & 4 & 2 \\
\hline 20 & Responden 20 & 50 & Laki-Laki & 3 & 1 & 3 & 3 & 4 & 1 & 3 & 1 & 3 & 2 \\
\hline 21 & Responden 21 & 32 & Laki-Laki & 3 & 2 & 4 & 2 & 4 & 2 & 4 & 2 & 4 & 3 \\
\hline 22 & Responden 22 & 34 & Laki-Laki & 4 & 2 & 3 & 2 & 5 & 2 & 4 & 2 & 4 & 1 \\
\hline 23 & Responden 23 & 23 & Laki-Laki & 3 & 2 & 5 & 2 & 4 & 1 & 5 & 2 & 4 & 2 \\
\hline 24 & Responden 24 & 24 & Laki-Laki & 4 & 2 & 4 & 2 & 5 & 2 & 5 & 2 & 4 & 2 \\
\hline 25 & Responden 25 & 35 & Laki-Laki & 4 & 2 & 3 & 2 & 5 & 1 & 5 & 2 & 4 & 1 \\
\hline 26 & Responden 26 & 36 & Laki-Laki & 3 & 2 & 4 & 2 & 5 & 1 & 5 & 3 & 4 & 2 \\
\hline 27 & Responden 27 & 29 & Laki-Laki & 3 & 2 & 4 & 2 & 5 & 2 & 4 & 2 & 4 & 1 \\
\hline 28 & Responden 28 & 25 & Laki-Laki & 4 & 2 & 5 & 2 & 4 & 2 & 4 & 2 & 4 & 1 \\
\hline
\end{tabular}


TABEL IVV

SKOR HASIL PERHITUNGAN SUS

\begin{tabular}{|c|c|c|c|c|c|c|c|c|c|c|c|c|}
\hline \multirow{2}{*}{ No } & \multicolumn{10}{|c|}{ Skor Hasil Hitung } & \multirow{2}{*}{ Jumlah } & \multirow{2}{*}{$\stackrel{\text { Nilai }}{(\text { Jumlah } \times 2.5)}$} \\
\hline & Q1 & Q2 & Q3 & Q4 & Q5 & Q6 & Q7 & \begin{tabular}{l|l} 
Q8 & \\
\end{tabular} & Q9 & Q10 & & \\
\hline 1 & 4 & 3 & 3 & 3 & 3 & 3 & 3 & 4 & 4 & 3 & 33 & 83 \\
\hline 2 & 2 & 1 & 4 & 4 & 4 & 3 & 2 & 4 & 4 & 2 & 30 & 75 \\
\hline 3 & 3 & 3 & 3 & 3 & 2 & 3 & 2 & 3 & 3 & 4 & 29 & 73 \\
\hline 4 & 4 & 2 & 4 & 2 & 4 & 3 & 4 & 2 & 4 & 2 & 31 & 78 \\
\hline 5 & 4 & 3 & 3 & 3 & 3 & 3 & 3 & 3 & 4 & 3 & 32 & 80 \\
\hline 6 & 2 & 3 & 2 & 3 & 3 & 2 & 4 & 3 & 3 & 3 & 28 & 70 \\
\hline 7 & 3 & 3 & 3 & 3 & 3 & 3 & 3 & 3 & 2 & 3 & 29 & 73 \\
\hline 8 & 2 & 3 & 3 & 3 & 4 & 2 & 4 & 3 & 2 & 4 & 30 & 75 \\
\hline 9 & 3 & 3 & 2 & 3 & 3 & 3 & 3 & 3 & 3 & 4 & 30 & 75 \\
\hline 10 & 3 & 3 & 3 & 2 & 3 & 3 & 3 & 3 & 2 & 3 & 28 & 70 \\
\hline 11 & 2 & 3 & 2 & 2 & 3 & 3 & 2 & 3 & 2 & 3 & 25 & 63 \\
\hline 12 & 4 & 3 & 3 & 3 & 3 & 4 & 1 & 2 & 3 & 2 & 28 & 70 \\
\hline 13 & 4 & 3 & 3 & 3 & 3 & 3 & 3 & 4 & 4 & 3 & 33 & 83 \\
\hline 14 & 3 & 3 & 4 & 3 & 3 & 4 & 2 & 3 & 3 & 3 & 31 & 78 \\
\hline 15 & 3 & 3 & 3 & 3 & 3 & 2 & 2 & 3 & 3 & 3 & 28 & 70 \\
\hline 16 & 2 & 3 & 2 & 3 & 3 & 4 & 2 & 3 & 4 & 3 & 29 & 73 \\
\hline 17 & 3 & 3 & 3 & 3 & 2 & 2 & 3 & 3 & 3 & 3 & 28 & 70 \\
\hline 18 & 2 & 4 & 3 & 4 & 2 & 4 & 3 & 4 & 2 & 3 & 31 & 78 \\
\hline 19 & 4 & 3 & 4 & 3 & 4 & 3 & 4 & 4 & 3 & 3 & 35 & 88 \\
\hline 20 & 2 & 4 & 2 & 2 & 3 & 4 & 2 & 4 & 2 & 3 & 28 & 70 \\
\hline 21 & 2 & 3 & 3 & 3 & 3 & 3 & 3 & 3 & 3 & 2 & 28 & 70 \\
\hline 22 & 3 & 3 & 2 & 3 & 4 & 3 & 3 & 3 & 3 & 4 & 31 & 78 \\
\hline 23 & 2 & 3 & 4 & 3 & 3 & 4 & 4 & 3 & 3 & 3 & 32 & 80 \\
\hline 24 & 3 & 3 & 3 & 3 & 4 & 3 & 4 & 3 & 3 & 3 & 32 & 80 \\
\hline 25 & 3 & 3 & 2 & 3 & 4 & 4 & 4 & 3 & 3 & 4 & 33 & 83 \\
\hline 26 & 2 & 3 & 3 & 3 & 4 & 4 & 4 & 2 & 3 & 3 & 31 & 78 \\
\hline 27 & 2 & 3 & 3 & 3 & 4 & 3 & 3 & 3 & 3 & 4 & 31 & 78 \\
\hline 28 & 3 & 3 & 4 & 3 & 3 & 3 & 3 & 3 & 3 & 4 & 32 & 80 \\
\hline & & & & kor & Zata-r & ata $(\mathrm{H}$ & [asil A & khir) & & & & 76 \\
\hline
\end{tabular}

Berdasarkan hasil perhitungan skor SUS menggunakan nilai rata-rata likert, diperoleh hasil akhir skor rata-rata sebesar 76 (garis merah). Berdasarkan SUS, rentang nilai usability dapat dilihat pada Gambar 23 .

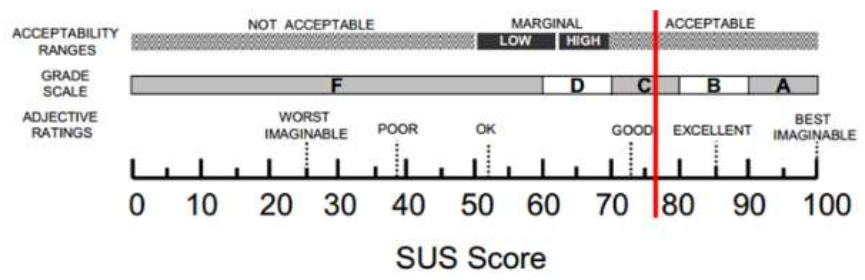

Gambar 23. Hasil interprestasi skor System Usability Scale (SUS)

Sistem informasi manajemen aset TI mendapatkan acceptability ranges dengan hasil acceptable, untuk grade scale dengan hasil $\mathrm{C}$ sedangkan pada adjective ratings dengan hasil good yaitu sebesar 76. Maka dari itu, website sistem informasi manajemen aset TI berhasil membangun sistem dengan tingkat usability yang baik.

\section{2) Pengujian Black-box}

Pengujian dilakukan oleh Baskoro Widiarso, S. Kom. selaku Kepala Urusan Pelayanan Komunikasi pada Sub Bidang Teknologi Komunukasi Bid TIK Polda Kepulauan
Riau, dilaksanakan bersamaan dengan pengambilan data untuk usability testing.

Pengujian black box yang telah dilakukan, menghasilkan bahwa seluruh kebutuhan fungsional dari sistem yang dibangun telah terpenuhi serta berfungsi dengan baik.

\section{KESIMPULAN}

Aplikasi pengelolaan aset telah berhasil dirancang mengikuti tahapan perancangan UCD sehingga menghasilkan aplikasi yang mudah digunakan. Aplikasi yang telah dibangun dapat melakukan pengelolaan aset sehingga bisa membantu Bid TIK dalam melakukan tata kelola aset dengan baik. Hasil pengujian Usability Testing dengan System Usability Scale, sistem informasi manajemen aset TI ada pada range acceptable, untuk grade scale dengan hasil $\mathrm{C}$ sedangkan pada adjective ratings dengan hasil good yaitu sebesar 76. Maka dari itu, sistem informasi manajemen aset TI berhasil membangun dengan tingkat usability yang baik. Hasil pengujian black-box, menghasilkan seluruh kebutuhan fungsional dari sistem yang dibangun telah terpenuhi dan berfungsi dengan baik.

\section{DAFTAR PUSTAKA}

[1] A. Puspaningrum and E. Sudarmilah, "Sistem Informasi Manajemen Peminjaman ( Studi Kasus: Pengelolaan Aset Dan Tata Ruang Taman Budaya Jawa Tengah )," Technol. J. Ilm., vol. 11, no. 1, pp. 37-45, 2020.

[2] Rencana Kerja Bidang Teknologi Informasi dan Komunikasi. Batam: Kepolisian Daerah Kepulauan Riau, 2019.

[3] R. Ramdani, M. Lestari, and N. W. Parwati, "Sistem Informasi Permintaan dan Pengadaan Barang untuk Instalasi VSAT di PT Telkomsat," J. Ris. dan Apl. Mhs. Inform., vol. 1, no. 01, pp. 126133, 2020, doi: 10.30998/jrami.v1i01.265.

[4] S. rizal Hidayatulloh, S. janu Hartati, and P. Sudarmaningtyas, "Rancang Bangun Sistem Informasi Manajemen Aset Teknologi Informasi Pada PT. PELINDO III Cabang Perak Surabaya," $J$. JSIKA, vol. 5, no. 2, pp. 1-7, 2017.

[5] I. S. Yatana Saputri, M. Fadhli, and I. Surya, "Penerapan Metode UCD (User Centered Design) Pada E-Commerce Putri Intan Shop Berbasis Web," J. Nas. Teknol. dan Sist. Inf., vol. 3, no. 2, pp. 269 278, Sep. 2017, doi: 10.25077/TEKNOSI.v3i2.2017.269-278.

E. Masayu, N. Rismawati, and A. Informatika, "Analisis Perancangan Sistem Informasi Manajemen Aset PT. Multi Traktor Utama Berbasis Java," J. Bit, vol. 16, no. 2, pp. 42-46, 2020.

[7] J. S. Mitchell, Physical Asset Management Handbook. Clarion Technical Publishers, 2002.

[8] Y. A. Rahman, E. D. Wahyuni, and D. S. Pradana, "Rancang Bangun Prototype Sistem Informasi Manajemen Program Studi Informatika Menggunakan Pendekatan User Centered Design," Repositor, vol. 2, no. 4, pp. 503-510, 2020, [Online]. Available: http://research-

report.umm.ac.id/index.php/sentra/article/view/3016/0.

[9] L. Albani and G. Lombardi (FIMI), "User Centred Design for EASYREACH,” no. November 2010, pp. 1-45, 2010.

[10] R. Dwiseptian and Dewi Agushinta, "Analisis Usability Pada Silpi Perusahaan Asuransi Nasional Dengan Metode Evaluasi Heuristik," Sist. J. Sist. Inf., vol. 9, no. 1, pp. 51-62, 2019.

[11] D. E. Kurniawan, A. Saputra, and P. Prasetyawan, "Perancangan Sistem Terintegrasi pada Aplikasi Siklus Akuntansi dengan Evaluasi Technology Acceptance Model (TAM)", RESTI, vol. 2, no. 1 , pp. 315 - 321, Apr. 2018. 
[12] J. Nielsen, Usability Engineering. Elsevier Science, 1994.

[13] A. P. Putra, F. Andriyanto, K. Karisman, T. D. M. Harti, and W. P. Sari, "Pengujian Aplikasi Point Of Sale Menggunakan Blackbox Testing," J. Bina Komput., vol. 2, no. 1, pp. 74-78, Feb. 2020, doi 10.33557/binakomputer.v2i1.757.

[14] J. Brooke, SUS - A quick and dirty usability scale. Usability
Eval.Ind, 1995

[15] A. Bangor, P. Kortum, and J. Miller, "Determining what individual SUS scores mean: Adding an adjective rating scale," J. usability Stud., vol. 4, no. 3, pp. 114-123, 2009, doi: 66.39.39.113. 